\title{
On the Cournot-Bertrand profit differential and the structure of unionisation in a managerial duopoly ${ }^{*}$
}

\author{
Revised version: July 3, 2015
}

\begin{abstract}
:
This paper deals with the issue of the Cournot-Bertrand profit differential by bringing together two different strands of the industrial organisation literature: managerial delegation and unionised oligopolies. Relative to unionisation, two alternative regimes are analysed and compared: "decentralised unionisation", involving firm-specific unions and "centralised unionisation", in which an industry-wide union sets a uniform wage for the entire industry. The "reversal result" - that is profits are higher under Bertrand than under Cournot - applies irrespective of the unionisation regime and for a very wide range of product differentiation. Moreover, it is more likely to occur when unionisation is decentralised than centralised and, especially when products are not too much differentiated, the profit differential in favour of price competition is also larger in the presence of firm-specific unions. However, if firms' owners not only delegate the choice of the strategic variable but also that of the competition regime, managers always opt to compete in quantities, thus generating an inefficient choice for owners.
\end{abstract}

JEL codes: J33, J51, L13

Keywords: Cournot vs. Bertrand competition, managerial delegation, unionised oligopoly, union structures

\footnotetext{
* We are extremely grateful to two anonymous referees for their comments and suggestions that have substantially improved the quality of the paper. Usual disclaimers apply.
} 


\section{Introduction}

A cornerstone result in duopoly theory is that firms' profits are higher when firms compete in quantities (à la Cournot) than when they compete in prices (à la Bertrand) if products are (imperfect) substitutes (instead, the opposite applies when goods are complements). Singh and Vives (1984) first showed this result building on Dixit's (1979) differentiated duopoly model with linear demand structure and exogenous (constant) marginal costs (see also: Cheng, 1985; Vives, 1985; Klemperer and Meyer, 1986; Okuguchi, 1987; Tanaka, 2001). This paper deals with the issue of the CournotBertrand profit differential by relaxing the hypothesis of firms' exogenous marginal costs. In so doing, it brings together two different strands of the Industrial Organisation (IO) literature: managerial delegation and unionised oligopolies, which represent important institutional features in real world markets.

Since Berle and Means (1932), economists have recognized that in large companies ownership and control are separate, and managers may be driven not just by pure profit maximisation. In the IO literature, starting from the seminal articles by Fersthman (1985), Vickers (1985), Fersthman and Judd (1987) and Sklivas (1987), several works have considered the impact of manipulating managerial behaviour in duopoly games by incentive contracts, in order to attain a strategic advantage. Instead, the literature on unionised oligopolies (e.g. Horn and Wolinsky, 1988; Dowrick, 1989; Naylor, 1999; Correa-López and Naylor, 2004; Lommerud et al., 2005; CorreaLópez, 2007) highlights the role played by unions in a vertical structure and, in particular, how this affects competition in the product market.

In a unionised oligopoly framework, Correa-López and Naylor (2004) analyse a decentralised wage-bargaining game played between firms and labour unions, showing that, due to the strategic effects induced by firm-specific unions competition, the standard result that profits are higher under Cournot competition when products are substitutes may be reversed. However, this actually applies only if unions are sufficiently powerful and distinctly oriented towards wages with respect to employment. Fanti and Meccheri (2011) build on Correa-López and Naylor (2004) and point out that the strategic inter-union competition effect is magnified by the presence of decreasing returns in production, making the reversal result a possible event in a wider range of situations, most 
notably also when unions are total wage-bill maximising (i.e. they attach the same weights to wages and employment).

The aim of this paper is twofold. On the one hand, it aims to analyse the issue of the Cournot-Bertrand profit differential when managerial delegation and unionisation interplay with one another. Despite the huge increase over the last few decades in studies regarding managerial delegation and unionised oligopolies, cross-fertilisation between such prominent strands of IO theory is still rare. Notable exceptions are represented by Szymanski (1994), Bughin (1995), Mauleon and Vannetelbosch (2006), Liao (2010, 2014), Chatterjee and Saha (2011), Fanti and Meccheri (2013a) and Meccheri and Fanti (2014), which extend the managerial delegation literature in various directions by introducing the presence of unions. However, to the best of our knowledge, no attention has been placed in this context on the classic issue of the Cournot-Bertrand relative profitability.

On the other hand, we also investigate the role played by alternative unionisation structures in affecting the relative profitability of different modes of competition in a managerial duopoly framework. Indeed, while Correa-López and Naylor (2004) and Fanti and Meccheri (2011) focus solely on decentralised unionisation to assess the role of inter-union competition in affecting the Cournot-Bertand profit differential, unionisation regimes differ substantially between countries. Specifically, one salient dimension that differentiates unionisation structures in real economies is the degree of wage setting centralisation (Calmfors and Driffill, 1988; Freeman, 1988; Layard and Nickell, 1999; Flanagan, 1999). At the industry level, an alternative regime to firm-specific unions and decentralised wage setting is represented by a completely centralised system, in which a single industry-wide union sets a standard uniform wage for the entire industry, according to the principle "equal pay for equal work" (Haucap and Wey, 2004). ${ }^{1}$ Obviously, in this latter case inter-union competition is absent but, at the same time, there could be other mechanisms than inter-union competition, affecting firms' profitability differently according to whether they compete in

\footnotetext{
${ }^{1}$ At the country level, while decentralized unionisation is largely predominant in Australia, UK, North America and Japan, a centralized wage setting regime representing all workers in an industry is widespread in Continental Europe (e.g. Flanagan, 1999).
} 
quantities or in prices, hence making the "reversal result" a possible event also under centralised wage setting. $^{2}$

Our main results can be summarised as follows. First, we show the when firms' owners delegate strategic (output or price) decisions to their managers and the labour market is unionised, profits are generally higher under Bertrand than under Cournot competition even if unions attach the same weights to wages and employment. More precisely, in such a framework, the standard result (i.e. profits are higher when firms compete in quantities) occurs only if products are strict substitutes. Moreover, this holds true irrespective of the unionisation regime. Undoubtedly, such findings make the "Cournot-Bertrand profit reversal" a much more general result with respect to what has been typically proved by the previous literature.

Secondly, even if the reversal result "dominates" irrespective of the unionisation regime, it is more likely to occur when unionisation is decentralised than centralised. Moreover, especially when products are not too much differentiated, the profit differential in favour of price competition is also larger in the presence of firm-specific unions. This also means that the lower the degree of wage setting centralisation (or, in other words, the more "flexible" the unionisation structure), the more likely firms may find it convenient to compete on prices.

Finally, while the previous findings are obtained (as in many works dealing with the Cournot-Bertrand profit differential) by comparing exogenously the (profit) results under alternative competition regimes, we also investigate the endogenous competition regime that would arise if firms' owners delegated this choice (together with that of the strategic variable) to the managers. In such a case, the managers always opt to compete in quantities, meaning that their choice is (generally) inefficient from the owners' viewpoint. This also opens up the opportunity for owners to coordinate their decisions on the (price) contract that should be offered to customers.

As already stressed, to the best of our knowledge, this is the first contribution which analyses the robustness of Singh and Vives's (1984) result on the Cournot-Bertrand profit ranking when two widespread real market features (namely, managerial delegation and unionisation) interact with one another. However, this topic represents a classic issue in the IO literature and several works have

\footnotetext{
${ }^{2}$ An example is provided in Fanti and Meccheri (2013b) for centralised unionisation and in the presence of decreasing returns to labour.
} 
tackled it in other contexts. In particular, the Cournot-Bertrand profit differential has been investigated in a duopoly framework with firms' asymmetric costs and demands (Dastidar, 1997; Amir and Jin, 2001; Zanchettin, 2006; Wang, 2008) or different production technologies (Mukherjee et al., 2012), in a repeated duopoly game (Lambertini, 1997), in an n-firm oligopoly market structure with vertical product differentiation (Häckner, 2000), in a managerial duopoly with relative profit delegation (Miller and Pazgal, 2001), in the presence of R\&D, quality investments and technology licensing (Delbono and Denicolò, 1990; Motta, 1993; Qiu, 1997; Symeonidis, 2003; Mukherjee, 2011; Li and Ji, 2010; Pal, 2010; Chang and Peng, 2012; Nguyen et al., 2014), in a network goods duopoly (Pal, 2014) also in the presence of managerial delegation (Bhattacharjee and Pal, 2013; Chirco and Scrimitore, 2013; Pal, 2015), in a mixed duopoly (Ghosh and Mitra, 2010; Matsumura and Ogawa, 2012; Scrimitore, 2013, 2014a, 2014b) also in the presence of labour unions (Choi, 2012), with renegotiation-proof or two-part tariff contracts (Manasakis and Vlassis, 2014; Alipranti et al., 2014), and in the presence of welfare concerns (Ghosh and Mitra, 2014). Hence our paper contributes to this literature by analysing a hitherto unexplored framework.

The remaining part of the paper is organised as follows. Section 2 introduces the basic framework. In Section 3, equilibrium profits under alternative competition regimes are derived in the presence of different unionisation structures (decentralised and centralised), and our main results on the Cournot-Bertrand profit differential are established. In Section 4, the endogenous choice of the competition regime by managers is investigated. Finally, Section 5 concludes with further comments, while more technical proofs are relegated to the final Appendix.

\section{Basic framework}

We consider a duopoly market where two identical firms produce differentiated products and compete over either quantities (à la Cournot) or prices (à la Bertrand). The inverse demand is given by:

$$
p_{i}\left(q_{i}, q_{j}\right)=1-q_{i}-\gamma q_{j}
$$


where $p$ denotes the price, $q_{i}$ and $q_{j}$ the outputs by the two firms (with $i, j=1,2$ and $i \neq j$ ), and $\gamma \in$ $(0,1)$ represents the degree of product differentiation. Specifically, we concentrate on the case in which products are substitutes (the higher is $\gamma$, the higher the degree of substitutability). ${ }^{3}$

Both firms use only labour to produce according to a production function with constant returns $q_{i}=l_{i}$, where $l_{i}$ represents the number of workers employed by firm $i$. The latter faces a wage per unit of labour (i.e. the marginal cost), $w_{i}<1$. Hence its cost function is given by:

$$
C_{i}\left(q_{i}\right)=w_{i} l_{i}=w_{i} q_{i}
$$

and its profits are $\pi_{i}=\left(p_{i}-w_{i}\right) q_{i}$, which, taking (1) into account, become:

$$
\pi_{i}=\left(1-Q-w_{i}\right) q_{i}
$$

where $Q=q_{i}+q_{j}$. We also assume that each firm's owner hires a manager and delegates the output decision to this manager. Each manager receives a fixed salary plus a bonus element, which is related to a weighted combination between firm profits and sales (van Witteloostuijn et al., 2007; Jansen et al., 2009). ${ }^{4}$ Formally, if firm i's profits are positive - otherwise there is no bonus manager $i$ receives a bonus that is proportional to:

$$
u_{i}=\pi_{i}+b_{i} q_{i}=\left(1-Q-w_{i}+b_{i}\right) q_{i}
$$

\footnotetext{
${ }^{3}$ In line with the above-mentioned previous studies (Correa-López and Naylor, 2004; Fanti and Meccheri, 2011) the standard result for the case of complements, i.e. $\gamma \in(-1,0)$, that profits are higher under Bertrand competition, is always confirmed (see Choi, 2012, for a partially different outcome obtained in a different framework).

${ }^{4}$ We also follow the standard assumption of the managerial delegation theory that the fixed component (salary) of the manager's compensation is chosen by the firm's owner, so that the manager gets exactly his/her opportunity cost, which is normalised to zero.
} 
where $b_{i}$ is the incentive parameter that is chosen by firm $i$ 's owner and may be either positive or negative, depending on whether the owner provides incentives or disincentives for the manager's choice of output (sales). Specifically, if $b_{i} \neq 0$, firm $i$ 's manager moves away from strict profitmaximisation, including the consideration of sales. This implies that he/she becomes a more $\left(b_{i}>0\right)$ or less $\left(b_{i}<0\right)$ aggressive seller in the market.

Relative to the wage, following the literature on unionised oligopolies, we admit that it is not exogenously given but is determined by unions. In particular, we consider a three-stage game, whose specific sequence of moves is as follows:

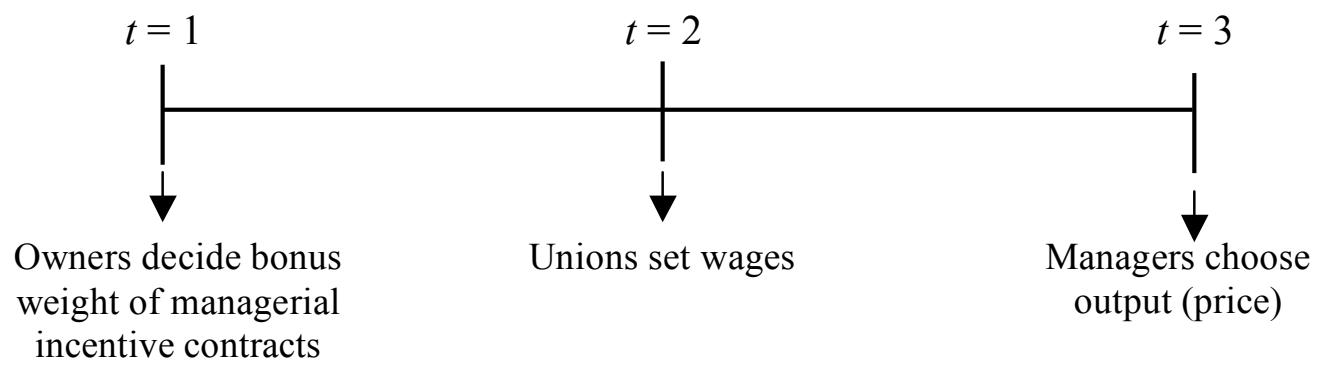

Fig. 1. Sequence of moves

As usual, the game is solved by backward induction. We consider now the sub-game equilibrium results for the final stage (the market game), ${ }^{5}$ while in the following section we concentrate on the previous stages by analysing two alternative unionisation structures.

When firms compete à la Cournot, at $t=3$, firm $i$ 's manager maximises (4) with respect to $q_{i}$. Taking into account that the manager of the firm $j$ behaves symmetrically, we can obtain firm $i$ 's output, for given wages and bonuses, as:

$$
q_{i}\left(w_{i}, w_{j}, b_{i}, b_{j}\right)=\frac{2-\gamma-2 w_{i}+\gamma w_{j}+2 b_{i}-\gamma b_{j}}{4-\gamma^{2}} .
$$

\footnotetext{
${ }^{5}$ Obviously, such results are standard and are reported here only because they will be useful for the analysis that follows in Section 3.
} 
Instead, when at $t=3$ firms compete à la Bertrand, taking (the inverse of) (1) into account, firm $i$ 's manager maximises his/her utility with respect to $p_{i}$. This leads to firm $i$ 's price, for given wages and bonuses:

$$
p_{i}\left(w_{i}, w_{j}, b_{i}, b_{j}\right)=\frac{2-\gamma-\gamma^{2}+2 w_{i}+\gamma w_{j}-2 b_{i}-\gamma b_{j}}{4-\gamma^{2}}
$$

which, considering the corresponding expression for $j$ and (1), also implies:

$$
q_{i}\left(w_{i}, w_{j}, b_{i}, b_{j}\right)=\frac{2-\gamma-\gamma^{2}-\left(2-\gamma^{2}\right) w_{i}+\gamma w_{j}+\left(2-\gamma^{2}\right) b_{i}-\gamma b_{j}}{\left(1-\gamma^{2}\right)\left(4-\gamma^{2}\right)}
$$

\section{Equilibrium profits under alternative unionisation structures (and competition regimes)}

\subsection{Decentralised unionisation}

In the presence of labour unions, the latter set wages at the second stage of the game (see Figure 1). In particular, we concentrate on monopoly unions, which maximise the total wage bill. When the structure of unionisation is decentralised, i.e. unions are firm-specific, the utility of firm $i$ 's union is given by:

$$
V_{i}=w_{i} l_{i}=w_{i} q_{i}
$$

Cournot competition. Under Cournot competition, unions maximise their objective functions with respect to wages, taking managers' output decisions into account. Substituting (5) in (8) and maximising with respect to $w_{i}$, we get: 


$$
w_{i}\left(w_{j}, b_{i}, b_{j}\right)=\frac{2-\gamma+\gamma w_{j}+2 b_{i}-\gamma b_{j}}{4}
$$

Notice that the unionised wage of firm $i$ depends positively (negatively) on the weight placed by the owner of firm $i$ (firm $j$ ) on sales. Eq. (9) defines the sub-game perfect best-reply function in wages of the union-firm pair $i$ under the assumption of a non-cooperative Cournot-Nash equilibrium in the product market. Solving the system composed by (9) and its counterpart for $j$, we obtain the sub-game perfect equilibrium wage:

$$
w_{i}\left(b_{i}, b_{j}\right)=\frac{8-2 \gamma-\gamma^{2}+\left(8-\gamma^{2}\right) b_{i}-2 \gamma b_{j}}{(4+\gamma)(4-\gamma)} .
$$

By substituting back in (5) and (3), we get profits as a function of the weights on sales alone:

$$
\pi_{i}\left(b_{i}, b_{j}\right)=\frac{2\left[(4+\gamma)(\gamma-2)-\left(8-\gamma^{2}\right) b_{i}+2 \gamma b_{j}\right]\left[(4+\gamma)(\gamma-2)+\left(48-18 \gamma+\gamma^{4}\right) b_{i}+4 \gamma b_{j}\right]}{\left(4-\gamma^{2}\right)^{2}\left(16-\gamma^{2}\right)^{2}} .
$$

At the first stage, each owner simultaneously chooses $b_{i}$, with the Nash equilibrium describing the outcome. In particular, by maximising (11) with respect to $b_{i}$, we get the reaction function for owner $i$ 's choice with respect to $b_{j}$ as:

$$
b_{i}\left(b_{j}\right)=-\frac{\left(32+\gamma^{4}-16 \gamma^{2}\right)\left(8-2 \gamma-\gamma^{2}-2 \gamma b_{j}\right)}{2\left(384-\gamma^{6}+26 \gamma^{4}-192 \gamma^{2}\right)} .
$$

In symmetric equilibrium $b_{i}=b_{j}=b$, and we get:

$$
b_{C}^{D}=-\frac{32+\gamma^{4}-16 \gamma^{2}}{2\left(48+\gamma^{4}-\gamma^{3}-16 \gamma^{2}+8 \gamma\right)}
$$


where the indexes $D$ and $C$ recall that the bonus refers to the case with decentralised unions and Cournot competition in the product market. Notice that, since $b_{C}^{D}<0$, owners will twist their manager's incentives away from sales, that is, it will be optimal for owners to "penalise" sales. The intuition behind this result is the following. As highlighted by the received literature on managerial delegation, choosing a positive weight on sales makes managers more aggressive as regards quantities (hence, demand for employment). However, this "competition effect" also has another important consequence in this framework: the higher the demand for employment by firms, the higher the unions' wage claims. As a consequence, by "penalising" quantities owners can instead put a brake on wage rises. In particular, when unionisation is decentralised, hence inter-union competition applies and firms' owners can obtain a large wage reduction by penalising sales, the "wage effect" outweighs the standard "competition effect". In turn, this implies that firms' owners get higher profits by fixing a negative bonus weight on sales. ${ }^{6}$

Finally, by substituting (13) back into (5), (10) and (11), we find the results in relation to the (sub-game perfect) equilibrium output, wage and profit of each firm:

$$
q_{C}^{D}=\frac{8-\gamma^{2}}{48+\gamma^{4}-\gamma^{3}-16 \gamma^{2}+8 \gamma} ; \quad w_{C}^{D}=\frac{32+\gamma^{4}-12 \gamma^{2}}{2\left(48+\gamma^{4}-\gamma^{3}-16 \gamma^{2}+8 \gamma\right)} ; \quad \pi_{C}^{D}=\frac{\left(8-\gamma^{2}\right)\left(48+\gamma^{4}-18 \gamma^{2}\right)}{2\left(48+\gamma^{4}-\gamma^{3}-16 \gamma^{2}+8 \gamma\right)^{2}} .
$$

Bertrand competition. Substituting for (7) into (8) and maximising with respect to $w_{i}$, we get the sub-game perfect best-reply function in wages of the union-firm pair $i$ under the assumption of Bertrand competition in the product market:

$$
w_{i}\left(w_{j}, b_{i}, b_{j}\right)=\frac{2-\gamma-\gamma^{2}+\gamma w_{j}+\left(2-\gamma^{2}\right) b_{i}-\gamma b_{j}}{2\left(2-\gamma^{2}\right)} .
$$

\footnotetext{
${ }^{6}$ On this point, we defer to the broader discussion of Section 3.3. See also Fanti and Meccheri (2013a) for further details.
} 
Solving the system composed by (15) and its counterpart for $j$, we obtain the sub-game perfect equilibrium wage:

$$
w_{i}\left(b_{i}, b_{j}\right)=\frac{8-2 \gamma-9 \gamma^{2}+\gamma^{3}+2 \gamma^{4}+\left(8-9 \gamma^{2}+2 \gamma^{4}\right) b_{i}-\left(2 \gamma-\gamma^{3}\right) b_{j}}{16-17 \gamma^{2}+4 \gamma^{4}} .
$$

Then, by substituting back in (7) and (3), profits as a function of the weights on sales are given by:

$$
\pi_{i}\left(b_{i}, b_{j}\right)=\frac{\left\{\begin{array}{l}
\left(\gamma^{2}-2\right)\left[\left(4+\gamma-2 \gamma^{2}\right)\left(2-\gamma-\gamma^{2}\right)+\left(8-9 \gamma^{2}+2 \gamma^{4}\right) b_{i}-\left(2-\gamma^{2}\right) \gamma b_{j}\right] \\
{\left[\left(4+\gamma-2 \gamma^{2}\right)\left(2-\gamma-\gamma^{2}\right)+\left(24-29 \gamma^{2}+10 \gamma^{4}-\gamma^{6}\right) b_{i}+\left(4-4 \gamma^{2}+\gamma^{4}\right) \gamma b_{j}\right]}
\end{array}\right]}{\left(16-17 \gamma^{2}+4 \gamma^{4}\right)^{2}\left(4-\gamma^{2}\right)^{2}\left(1-\gamma^{2}\right)} .
$$

At the first stage, firms' owners maximise profit with respect to bonus weights, which leads to the reaction function for owner $i$ 's choice with respect to $b_{j}$ as:

$$
b_{i}\left(b_{j}\right)=\frac{\left(32-32 \gamma^{2}+7 \gamma^{4}\right)\left[8-2 \gamma-9 \gamma^{2}+\gamma^{3}+2 \gamma^{4}-\left(2 \gamma-\gamma^{3}\right) b_{j}\right]}{4\left(8-9 \gamma^{2}+2 \gamma^{4}\right)\left(29 \gamma^{2}-10 \gamma^{4}+\gamma^{6}-24\right)}
$$

and, taking the (symmetric) reaction function of owner $j$ into account, we get the equilibrium bonus weight as follows:

$$
b_{B}^{D}=-\frac{(1-\gamma)\left(32-32 \gamma^{2}+7 \gamma^{4}\right)}{96-80 \gamma-128 \gamma^{2}+102 \gamma^{3}+50 \gamma^{4}-37 \gamma^{5}-6 \gamma^{6}+4 \gamma^{7}}
$$

where the indexes $D$ and $B$ recall that the bonus refers to the case with decentralised unions and Bertrand competition in the product market. Since $b_{B}^{D}<0$, owners will twist their manager's incentives away from sales also when firms compete in prices. In other words, when unionisation is decentralised, it will be optimal for owners to "penalise" sales irrespective of the competition 
regime in the product market. Notice, however, that while in the Cournot case (analysed above) the standard result (i.e. a positive bonus weight) is reversed by the presence of (decentralised) unionisation, the fact that under Bertrand owners penalise sales is a standard outcome in the managerial delegation literature, which is here confirmed also in the presence of unionisation.

Finally, by substituting back in (7), (16) and (17), we obtain the equilibrium output, wage and profit for this case:

$$
\begin{gathered}
q_{B}^{D}=\frac{16-2 \gamma^{6}+13 \gamma^{4}-26 \gamma^{2}}{96-80 \gamma-128 \gamma^{2}+102 \gamma^{3}+50 \gamma^{4}-37 \gamma^{5}-6 \gamma^{6}+4 \gamma^{7}} ; \\
w_{B}^{D}=\frac{32-32 \gamma-44 \gamma^{2}+44 \gamma^{3}+17 \gamma^{4}-17 \gamma^{5}-2 \gamma^{6}+2 \gamma^{7}}{96-80 \gamma-128 \gamma^{2}+102 \gamma^{3}+50 \gamma^{4}-37 \gamma^{5}-6 \gamma^{6}+4 \gamma^{7}} \\
\pi_{B}^{D}=\frac{2\left(8-9 \gamma^{2}+2 \gamma^{4}\right)\left(48-48 \gamma-82 \gamma^{2}+82 \gamma^{3}+49 \gamma^{4}-49 \gamma^{5}-12 \gamma^{6}+12 \gamma^{7}+\gamma^{8}-\gamma^{9}\right)}{(1+\gamma)\left(96-80 \gamma-128 \gamma^{2}+102 \gamma^{3}+50 \gamma^{4}-37 \gamma^{5}-6 \gamma^{6}+4 \gamma^{7}\right)^{2}} .
\end{gathered}
$$

\subsection{Centralised unionisation}

When unionisation is centralised, following the principle of "equal pay for equal work", the central union institutionally fixes a uniform wage for the industry as a whole (e.g. Haucap and Wey, 2004). So, in such a case, we can assume from the outset that $w_{i}=w_{j}=w$ and the union's utility function becomes: ${ }^{7}$

$$
V=w\left(l_{i}+l_{j}\right)=w\left(q_{i}+q_{j}\right) \text {. }
$$

Cournot competition. After substitution of (5) and the corresponding equation for $j$, at the second stage, the union maximises (21) with respect to $w$, which leads to:

\footnotetext{
${ }^{7}$ Clearly, as now there is only one union, we do not need to use an index anymore to denote it. Also notice that, when unionisation is centralised, all equations above from (2) to (7) apply with $w_{i}=w_{j}=w$.
} 


$$
w\left(b_{i}, b_{j}\right)=\frac{2+b_{i}+b_{j}}{4} .
$$

By substituting for $w$ in (5) and (3), we get profits as a function of the weights on sales as:

$$
\pi_{i}\left(b_{i}, b_{j}\right)=\frac{\left[4-2 \gamma+(6+\gamma) b_{i}-(2+3 \gamma) b_{j}\right]\left[4-2 \gamma-\left(10-\gamma-4 \gamma^{2}\right) b_{i}-(2+3 \gamma) b_{j}\right]}{16\left(4-\gamma^{2}\right)^{2}}
$$

and maximising with respect to $b_{i}$, we get the reaction function for an owner's choice of $b_{i}$ with respect to $b_{j}$ as:

$$
b_{i}\left(b_{j}\right)=-\frac{8-8 \gamma-6 \gamma^{2}+4 \gamma^{3}-\left(4+4 \gamma-7 \gamma^{2}-6 \gamma^{3}\right) b_{j}}{60+4 \gamma-25 \gamma^{2}-4 \gamma^{3}}
$$

from which, taking the (symmetric) reaction function of owner $j$ into account, we obtain the equilibrium bonus weight:

$$
b_{C}^{C}=-\frac{2-\gamma-2 \gamma^{2}}{14+7 \gamma-\gamma^{2}}
$$

where the indexes $C$ and $C$ refer to Cournot and to the centralized union, respectively. Then, by substituting back into (5), (22) and (23) we get the equilibrium output, wage and profit for this case:

$$
q_{C}^{C}=\frac{6+\gamma}{2\left(14+7 \gamma-\gamma^{2}\right)} ; \quad w_{C}^{C}=\frac{12+\gamma^{2}+8 \gamma}{2\left(14+7 \gamma-\gamma^{2}\right)} ; \quad \pi_{C}^{C}=\frac{(6+\gamma)\left(10-\gamma-4 \gamma^{2}\right)}{4\left(14+7 \gamma-\gamma^{2}\right)^{2}} .
$$

Bertrand competition. Finally, we consider the case in which unionisation is centralised and firms compete in prices. At stage 2, the central union maximises (21), taking (7) and the corresponding for $j$ into account, which leads to: 


$$
w\left(b_{i}, b_{j}\right)=\frac{2+b_{i}+b_{j}}{4} .^{8}
$$

By substituting for (27), in firm $i$ 's profit equation, we obtain:

$$
\pi_{i}\left(b_{i}, b_{j}\right)=\frac{\left[4-2 \gamma-2 \gamma^{2}+\left(6+\gamma-\gamma^{2}\right) b_{i}-\left(2+3 \gamma-\gamma^{2}\right) b_{j}\right]\left[4-2 \gamma-2 \gamma^{2}-\left(10-\gamma-\gamma^{2}\right) b_{i}-\left(2+3 \gamma-\gamma^{2}\right) b_{j}\right]}{16\left(1-\gamma^{2}\right)\left(4-\gamma^{2}\right)^{2}}
$$

and maximising (at stage 1) with respect to $b_{i}$, we get the following reaction function for owner $i$ :

$$
b_{i}\left(b_{j}\right)=-\frac{\left(2-\gamma+\gamma^{2}\right)\left[4-2 \gamma-2 \gamma^{2}-\left(2+3 \gamma-\gamma^{2}\right) b_{j}\right]}{\left(6+\gamma-3 \gamma^{2}\right)\left(10-\gamma-\gamma^{2}\right)} .
$$

Taking the (symmetric) reaction function of owner $j$ into account, we get the equilibrium bonus weight:

$$
b_{B}^{C}=\frac{(\gamma-1)\left(2-\gamma+\gamma^{2}\right)}{14-7 \gamma-5 \gamma^{2}+2 \gamma^{3}} \text {. }
$$

where the indexes $B$ and $C$ refer to Bertrand and centralised unionisation, respectively. Finally, by substituting back into (7), (27) and (28), we get the equilibrium output, wage and profit:

\footnotetext{
${ }^{8}$ Notice that, when unionisation is centralised, the union's reaction function in wage for given bonus weights is the same under Cournot and Bertrand competition. This recalls the well-known Dhillon and Petrakis' (2002) "wage rigidity result", according to which, as long as wage setting is centralised at an industry level, wages are the same irrespective of a wide range of product market characteristics, including the competition regime. However, since the bonus weights chosen by owners at the previous stage differ according to the competition regime, also (equilibrium) wages will be different and, in this framework, the "wage rigidity result" does not apply in the sub-game perfect equilibrium.
} 


$$
q_{B}^{C}=\frac{6+\gamma-3 \gamma^{2}}{2(1+\gamma)\left(14-7 \gamma-5 \gamma^{2}+2 \gamma^{3}\right)} ; \quad w_{B}^{C}=\frac{12+3 \gamma^{3}-7 \gamma^{2}-4 \gamma}{2\left(14-7 \gamma-5 \gamma^{2}+2 \gamma^{3}\right)} ; \quad \pi_{B}^{C}=\frac{\left(6+\gamma-3 \gamma^{2}\right)\left(10-11 \gamma+\gamma^{3}\right)}{4(1+\gamma)\left(14-7 \gamma-5 \gamma^{2}+2 \gamma^{3}\right)^{2}} .
$$

\subsection{Discussion of the "wage effect" and the bonus weights under alternative regimes}

In this section we discuss in greater depth the outcomes derived above. In particular, we investigate how the "wage effect", which is crucial in this framework and relates to the presence of unions in determining wages, is differently affected by the degree of product differentiation under alternative competition and unionisation regimes. Moreover, we compare and discuss the different sizes of the bonus weights in different regimes, as well as their behaviour according to parameter $\gamma$. This will be useful for a better understanding of the main results that will be obtained in Section 3.4.

As already mentioned, a key point in this framework is represented by the fact that, together with the standard "competition effect" highlighted by the received literature on managerial delegation without unions, in which marginal costs, i.e. wages of (non-managerial) workers, are exogenously given, another important effect plays a role in determining the owners' choice of the bonus weight in managerial contracts. This effect, that has been labelled "wage effect", refers to the possibility for owners to dampen the unions' wage claim by penalising sales (that is, by choosing a negative bonus weight). Hence, the wage effect captures the sensitivity of wages with respect to the bonus weights in managerial contracts. Figure 2 shows the size of the wage effect under alternative (competition and unionisation) regimes, as well as its behaviour according to the degree of product differentiation/substitutability. ${ }^{9}$

\footnotetext{
${ }^{9}$ In a nutshell, the "wage effect" is measured by the changes in the unionised wage due to the choice of bonus. In particular, under decentralised unionisation, the wage effect is computed by deriving $w_{i}\left(w_{j}, b_{i}, b_{j}\right)$ with respect to $b_{i}$, taking $w_{j}\left(b_{i}, b_{j}\right)$ and $b_{j}\left(b_{i}\right)$ into account (for instance, under Cournot competition, it is obtained by deriving (9) with respect to $b_{i}$, taking the corresponding of (10) and (12) for $j$ into account). Instead, when unionisation is centralised, it is obtained by deriving $w\left(b_{i}, b_{j}\right)$ with respect to $b_{i}$, taking $b_{j}\left(b_{i}\right)$ into account (for instance, under Cournot competition, it is obtained by deriving (22) with respect to $b_{i}$, taking the corresponding of (24) for $j$ into account).
} 


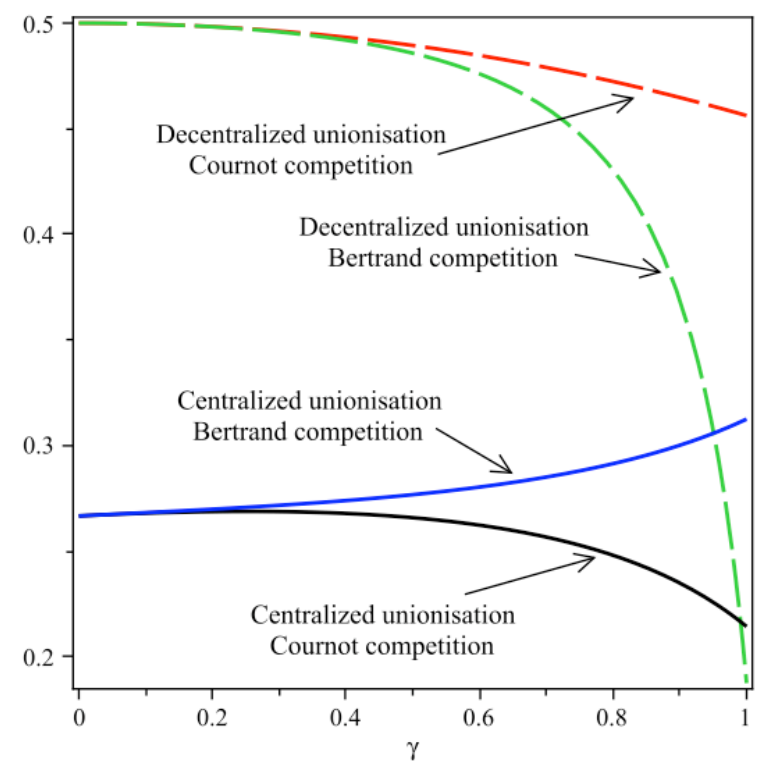

Fig. 2. "Wage effect" according to $\gamma$ under alternative regimes

First, note that, as expected, the wage effect is always positive: the higher the bonus weight, the higher the wage chosen by union(s) for (non-managerial) workers. Thus, in order to obtain a wage reduction by the union, firms' owners have an incentive to reduce the bonus weight for managers and, possibly, also to set a negative bonus. Secondly, the wage effect is generally stronger when unionisation is decentralised. Indeed, under firm-specific unions, this effect is magnified by the presence of inter-union competition, ${ }^{10}$ which is clearly absent in the presence of a single industry-wide union. In other words, under decentralisation, inter-union competition makes wages more flexible with respect to the bonus weight while, in the presence of a central union, the wage is "stickier".

Relative to the role played by $\gamma$, when firms compete in strategic substitutes (à la Cournot), the wage effect decreases as $\gamma$ increases irrespective of the unionisation regime. Consider, for instance, an increase in $b_{i}$. Together with an increase in $q_{i}$, it also leads to a reduction in $q_{j}$, which is greater, the higher the degree of product substitutability. In both unionisation regimes, this produces

\footnotetext{
${ }^{10}$ See, however, the particular case of Bertrand competition with a very high degree of product substitutability, discussed below.
} 
a less sizable wage change for firm $i$ as a consequence of the initial increase in $b_{i}$ (i.e. a reduced wage effect). ${ }^{11}$

Instead, when firms compete in strategic complements (à la Bertrand), the behaviour of the wage effect with respect to $\gamma$ may be different with respect to that analysed under Cournot competition, in particular depending on whether the unionisation is centralised or decentralised. Indeed, when unionisation is centralised, the wage effect increases with $\gamma$, which makes sense. In strategic complements (and considering again the previous example), the reduction in $p_{i}$ following an increase in $b_{i}$ is also magnified by a decrease in $p_{j}$ : the higher the degree of product substitutability, the greater the decrease. Both price reductions lead, in turn, to an increase in output and, as a consequence, in labour demand by firms. Since the higher the (total) demand for employment, the higher the wage claim by the union, this explains the positive relationship between the increase in the union's wage (initially originated by that of $b_{i}$ ) and $\gamma$. By contrast, when unionisation is decentralised, also inter-union competition is known to arise and its role on the relationship between the wage effect and the degree of product differentiation is twofold. On the one hand, as discussed above, it makes wages more flexible with respect to the bonus weight, explaining why the wage effect is stronger when the degree of product substitutability is low. On the other, it reduces wages when $\gamma$ increases, until they become zero (the workers' reservation wage) when $\gamma \rightarrow$ 1. ${ }^{12}$ Hence, under decentralization (and Bertrand competition in the product market), the wage effect

\footnotetext{
${ }^{11}$ Note, however, that the reason for this occurring differs in the alternative unionisation regimes. On the one hand, if unionisation is decentralized, when $q_{j}$ decreases, so does $w_{j}$. Since $w_{i}$ and $w_{j}$ are positively correlated, the reduction in $w_{j}$ makes the increase of $w_{i}$ less sizable following that of $q_{i}$. On the other hand, when unionisation is centralised, the total demand for employment increases less proportionally than $q_{i}$ when $q_{j}$ decreases, and this makes the increase in $w$ decided by the central union less sizable.

${ }^{12}$ Indeed, from (20), it is easy to check that $w^{D}{ }_{B} \rightarrow 0$ when $\gamma \rightarrow 1$. Also note that the same qualitative result does not apply when firms compete in quantities, i.e. $w_{C}^{D}$ is strictly positive even when $\gamma \rightarrow 1$ (see (14)). This is in line with the result of Correa-López and Naylor (2004, p. 690) in a unionised duopoly without managerial delegation that "[a firm-specific union] has a stronger incentive to settle for a lower bargained wage rate when facing a Bertrand-type competitor in the product market" because "the sub-game perfect labor demand schedule derived under Bertrand competition in the product market is more elastic than the sub-game perfect labor demand schedule derived under Cournot competition".
} 
tends to reduce with an increasing $\gamma$ and collapses to zero as $\gamma$ becomes sufficiently large since, when wages are very low, there is no room for firms' owners to obtain a further wage reduction by relying on the bonus weight.

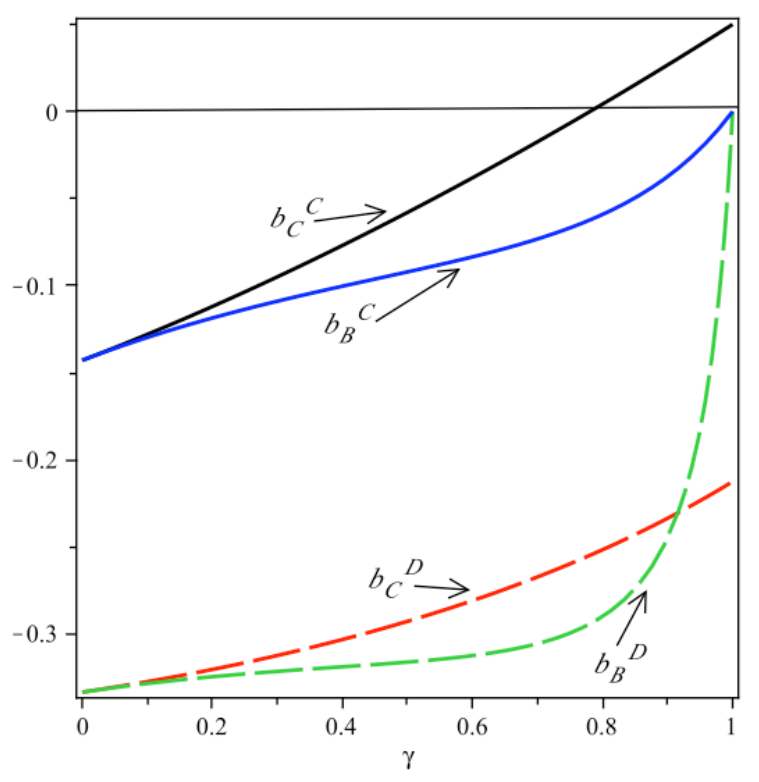

Fig. 3. Bonus behaviour according to $\gamma$ under alternative regimes

Figure 3 shows the behaviour of the (equilibrium) bonus weight under the alternative regimes and according to parameter $\gamma$. Also in the light of the discussion above on the "wage effect", some results are quite intuitive. First, given the unionisation regime, the penalisation provided by the firms' owners on sales to the managers or, in other words, the size of the negative bonus weight, is generally larger when firms compete in prices. This is mainly due to the fact that, as highlighted by the literature on managerial delegation without unions, when firms compete in strategic complements also the standard "competition effect" drives owners to penalise managers for sales (e.g. Fershtman and Judd, 1987; Sklivas, 1987). ${ }^{13}$ Hence, in this case, the "competition effect" and the "wage effect" operate in the same direction for a negative bonus weight. In other words, while

\footnotetext{
${ }^{13}$ For instance Fershtman and Judd (1987, p. 938), conclude that "in the price competition case, each owner knows that any credible increase in its own price will be followed by an increase in its rival's price, therefore motivating its manager to be less aggressive".
} 
under Cournot the competition effect "softens" the wage effect in determining a negative bonus weight, under Bertrand competition they reinforce one another. This leads to a higher (negative) size of the bonus when firms compete in prices. There is, however, an important exception. When unionisation is decentralised, the bonus weight is lower (in absolute value) under price competition when products are strictly substitutes (i.e. when $\gamma$ approaches one). In fact, this is simply due to the fact that when $\gamma \rightarrow 1$, both the wage effect and the competition effect vanish: the wage effect for the reason explained above, while the competition effect for the "Bertrand paradox" that profits collapse to zero when firms compete in prices and goods are homogeneous. As a consequence, the optimal bonus weight is zero. Thus, as $\gamma$ is sufficiently close to one, it becomes lower (in absolute value) under price competition than under quantity competition (where the bonus remains negative even when $\gamma \rightarrow 1)$.

Given instead the competition regime, the penalisation over sales is higher when unionisation is decentralised: this is in line with the above discussion on the wage effect, which is higher under decentralised unionisation. In this respect, it is worth noting further that there is a subtle but crucial difference between the cases of centralised and decentralised unionisation in relation to the owners' incentive to relatively "penalise" output to keep employment demand low, thereby dampening wage claims. Under firm-specific unions, each owner, when providing her/his manager with incentives to reduce output, knows exactly how the union will react in terms of wage. Instead, under a central union, each owner's instruction to reduce output (employment) will impact on the wage claims in her/his firm only partially because the latter also depends on the output of the rival firm. This means that, under centralisation, the "spillover effect" of each incentive contract on the rival firm's wage claims, on the one hand, reduces the strategic effect of the manager's contract on the wage claims by the union and, on the other, it introduces a "free-rider" effect in the owner's behaviour, which also contributes to making the penalization on sales for managers less severe in such a unionisation regime.

Finally, also the behaviour of the bonus weights with respect to $\gamma$ is in line with what is expected. In particular, under Cournot competition, the penalisation diminishes with $\gamma$. The reason is twofold. On the one hand, the competition effect (which under Cournot pushes for a positive bonus weight) is stronger when the degree of product substitutability increases. On the other, the wage 
effect tends to weaken when product differentiation decreases. This also explains why, when unionisation is centralised (and the wage effect is generally less strong), there exists a threshold for $\gamma$, above which the competition effect outweighs the wage effect. Hence the bonus weight becomes positive, that is, owners provide managers with incentives for sales. ${ }^{14}$ Under Bertrand competition, instead, the bonus weight is always negative irrespective of the unionisation regime and tends to zero in the limit case of the model (the Bertrand paradox) when products become perfect substitutes, also implying that, under decentralisation, there exists a threshold for $\gamma$ very close to one, above which the negative bonus is larger under Cournot. ${ }^{15}$

\subsection{Cournot-Bertrand profit differentials}

In this section, by exploiting the equilibrium outcomes obtained in the previous sections, we analyse the issue of the Cournot-Bertrand profit differential in a framework with a unionised labour market and managerial delegation.

Proposition 1. Considering a duopoly framework where strategic decisions are delegated to managers, (non-managerial) wages are set by total wage-bill maximising unions and firms' products are (imperfect) substitutes, that is $\gamma \in(0,1)$, profits are higher when firms compete in prices instead of in quantities, when unionisation is decentralised, unless products are strict substitutes (i.e. for $\gamma<0.964)$ and, when unionisation is centralised, when product differentiation is sufficiently high (i.e. $\gamma<0.761$ ).

Proof. See the final appendix.

\footnotetext{
${ }^{14}$ The threshold for $\gamma$ above which, under Cournot competition and centralised unionisation, the bonus weight is positive is 0.7808 .

${ }^{15}$ This threshold for $\gamma$ is 0.9159 (we are grateful to a referee for having suggested this point).
} 
This result reveals the importance of the interplay between managerial delegation and unionisation in determining the relative profitability of the modes of competition. Indeed, while previous analysis with decentralised unionisation (without managerial delegation) suggested that, when unions are total wage-bill maximising, attaching the same weights to wage and employment, profit reversal cannot occur (Correa-López and Naylor 2004), in this context in which unionisation and managerial delegation are considered together, it almost always occurs.

Corollary. According to Proposition 1, when firms' owners delegate strategic decisions to managers, the reversal result that profits are higher under Bertrand than under Cournot when products are substitutes is more likely to apply when unionisation is decentralized than centralized.

Proof. It trivially follows by noting that the threshold $\bar{\gamma}^{D}$, below which "profit reversal" applies under decentralised unionisation, is higher than the threshold $\bar{\gamma}^{C}$, below which it applies with centralised unionisation.

The corollary, that the "profit reversal" result is more likely to occur under decentralised unionisation, can be explained according to the discussion on the bonus weights under alternative unionisation and competition regimes. Indeed, as discussed above, the penalisation on sales (i.e. the negative bonus weight) that permits owners to reduce unions' wage claims and increase profits is stronger when firms compete $a ̀$ la Bertrand and especially when unionisation is decentralised. 


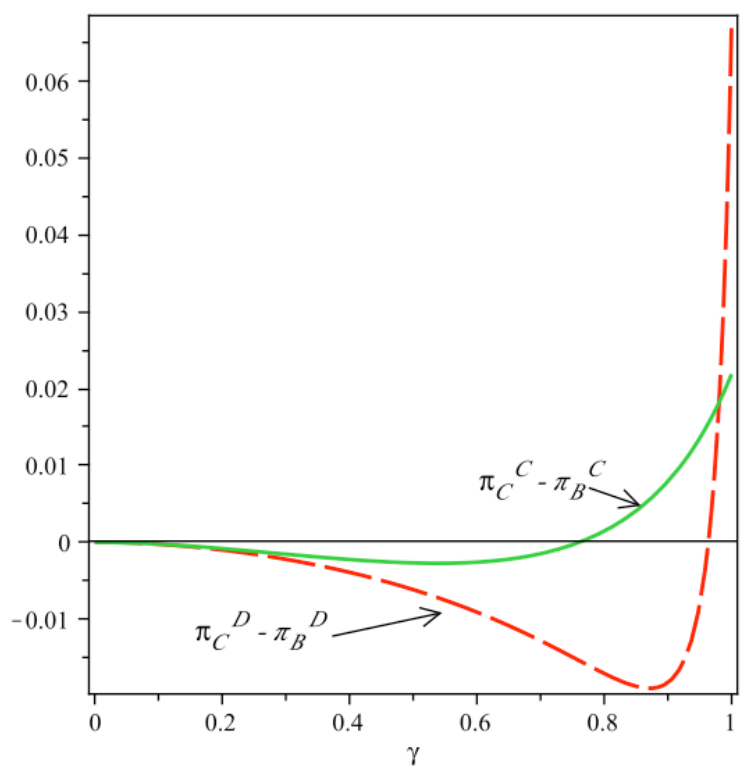

Fig. 4. Cournot-Bertrand profit differential $\left(\pi_{C}-\pi_{B}\right)$ under different unionisation regimes

A graphical proof of the results outlined above is provided by Figure 4. Note that, when unionisation is decentralised, not only is the "reversal result" that profits are larger under Bertrand more likely to apply (because the threshold below which it occurs is higher), but the profit differential in favour of price competition is larger in such a union regime, especially when products are not too much differentiated (i.e. when $\gamma$ is sufficiently high).

\section{$4 \quad$ Endogenous competition choice by managers}

The analysis of whether the Cournot or the Bertrand competition is more profitable for firms is an important issue of the industrial organisation literature per se, as witnessed by the numerous contributions that deal with the issue by comparing the profit results under alternative (exogenous) competition regimes (e.g. Häckner, 2000; Correa-López and Naylor, 2004; Zanchettin, 2006). However, it is worth extending the above framework by also investigating the endogenous choice of the competition regime by managers. In particular, we assume now that, before playing the product 
market game, managers choose the type of contract (price or quantity) to be offered to customers that maximises their objective given by (4). ${ }^{16}$

With respect to the previous analysis, in order to assess which type of contract will be actually offered by managers we have to consider also the equilibrium results when firms behave asymmetrically in the product market, that is, a firm behaves as a Cournot-type, while the other firm as a Bertrand-type. Again, in the market game (at the final stage), managers make their strategic choices simultaneously under complete information. Firms face symmetric inverse demand and cost functions and differ only in their choice of strategic variable: one firm's manager maximises her/his utility with respect to output, taking wages, bonuses and the price of the rival firm as given, while the other firm's manager maximises her/his utility with respect to price, taking wages, bonuses and the output of the rival as given. The game then proceeds through standard analysis.

For sake of space, for the (asymmetric) case considered in this section, we only present the final results that are relevant to the analysis. ${ }^{17}$ In particular, by defining with the subscript $C / B$ the result of the firm that competes à la Cournot when the rival competes à la Bertrand and, viceversa, with the subscript $B / C$, the following outcomes for the bonus weight, output and profits apply in the (sub-game perfect) equilibrium under decentralised unionisation:

$$
\begin{gathered}
b_{C / B}^{D}=-\frac{\left(48+16 \gamma^{4}+5 \gamma^{3}-56 \gamma^{2}-8 \gamma\right)\left(32+17 \gamma^{4}-48 \gamma^{2}\right)}{\left(2-\gamma^{2}\right)\left(2304-697 \gamma^{6}+3136 \gamma^{4}-4672 \gamma^{2}\right)} ; \quad q_{C / B}^{D}=\frac{\left(8-5 \gamma^{2}\right)\left(48+16 \gamma^{4}+5 \gamma^{3}-56 \gamma^{2}-8 \gamma\right)}{2304-697 \gamma^{6}+3136 \gamma^{4}-4672 \gamma^{2}} \\
\pi_{C / B}^{D}=\frac{2\left(8-5 \gamma^{2}\right)\left(24+11 \gamma^{4}-33 \gamma^{2}\right)\left(48+16 \gamma^{4}+5 \gamma^{3}-56 \gamma^{2}-8 \gamma\right)^{2}}{\left(2-\gamma^{2}\right)\left(2304-697 \gamma^{6}+3136 \gamma^{4}-4672 \gamma^{2}\right)^{2}}
\end{gathered}
$$

and

\footnotetext{
${ }^{16}$ We owe this point, hence the extension of this section, to an anonymous referee. Notice that while the case suggested by the referee, that the managers choose the type of contracts (i.e. the mode of competition), is important and interesting, another possible scenario is that firms' owners retain this choice for themselves (e.g. Chirco and Scrimitore, 2013; Bhattacharjee and Pal, 2013; Pal, 2015). We defer the analysis in our framework of this alternative scenario to the future research.

${ }^{17}$ Formal derivations and further details are available from the authors upon request. [They were submitted in a separate file as additional material for reviewers]
} 


$$
\begin{gathered}
b_{B / C}^{D}=-\frac{\left(32+7 \gamma^{4}-32 \gamma^{2}\right)\left(96-5 \gamma^{5}+42 \gamma^{4}+18 \gamma^{3}-128 \gamma^{2}-16 \gamma\right)}{2\left(2-\gamma^{2}\right)\left(2304-697 \gamma^{6}+3136 \gamma^{4}-4672 \gamma^{2}\right)} ; \\
q_{B / C}^{D}=\frac{\left(8-5 \gamma^{2}\right)\left(96-5 \gamma^{5}+42 \gamma^{4}+18 \gamma^{3}-128 \gamma^{2}-16 \gamma\right)}{\left(2-\gamma^{2}\right)\left(2304-697 \gamma^{6}+3136 \gamma^{4}-4672 \gamma^{2}\right)} ; \\
\pi_{B / C}^{D}=\frac{\left(8-5 \gamma^{2}\right)\left(24-17 \gamma^{2}\right)\left(96-5 \gamma^{5}+42 \gamma^{4}+18 \gamma^{3}-128 \gamma^{2}-16 \gamma\right)^{2}}{2\left(2-\gamma^{2}\right)\left(2304-697 \gamma^{6}+3136 \gamma^{4}-4672 \gamma^{2}\right)^{2}} .
\end{gathered}
$$

Instead, when unionisation is centralised, equilibrium results are the following (where $\left.X \equiv 3584-7 \gamma^{10}-78 \gamma^{9}+25 \gamma^{8}+1108 \gamma^{7}-176 \gamma^{6}-5044 \gamma^{5}+2096 \gamma^{4}+8672 \gamma^{3}-5248 \gamma^{2}-4928 \gamma\right)$ :

$$
\begin{gathered}
b_{C / B}^{C}=-\frac{\left(4+2 \gamma^{4}+4 \gamma^{3}-7 \gamma^{2}-4 \gamma\right)\left(4-\gamma^{2}-2 \gamma\right)\left(32+\gamma^{4}+13 \gamma^{3}-16 \gamma^{2}-28 \gamma\right)}{X} ; \\
q_{C / B}^{C}=\frac{(2-\gamma)\left(6-\gamma^{3}-4 \gamma^{2}+\gamma\right)\left(4-\gamma^{2}-2 \gamma\right)\left(32+\gamma^{4}+13 \gamma^{3}-16 \gamma^{2}-28 \gamma\right)}{2 X} ; \\
\pi_{C / B}^{C}=\frac{(1-\gamma)(2-\gamma)\left(6-\gamma^{3}-4 \gamma^{2}+\gamma\right)\left(20-5 \gamma^{3}-15 \gamma^{2}+8 \gamma\right)\left(4-\gamma^{2}-2 \gamma\right)^{2}\left(32+\gamma^{4}+13 \gamma^{3}-16 \gamma^{2}-28 \gamma\right)^{2}}{4 X^{2}}
\end{gathered}
$$

and

$$
\begin{gathered}
b_{B / C}^{C}=-\frac{(1-\gamma)\left(4-2 \gamma^{4}+2 \gamma^{3}+\gamma^{2}-4 \gamma\right)\left(4-\gamma^{2}-2 \gamma\right)\left(32+\gamma^{4}-3 \gamma^{3}-24 \gamma^{2}+4 \gamma\right)}{X} ; \\
q_{B / C}^{C}=\frac{(1-\gamma)(2+\gamma)(6-5 \gamma)\left(4-\gamma^{2}-2 \gamma\right)\left(32+\gamma^{4}-3 \gamma^{3}-24 \gamma^{2}+4 \gamma\right)}{2 X} ; \\
\pi_{B / C}^{C}=\frac{(1-\gamma)^{2}(2+\gamma)(6-5 \gamma)\left(20+\gamma^{4}+8 \gamma^{3}-15 \gamma^{2}-12 \gamma\right)\left(4-\gamma^{2}-2 \gamma\right)^{2}\left(32+\gamma^{4}-3 \gamma^{3}-24 \gamma^{2}+4 \gamma\right)^{2}}{4 X^{2}} .
\end{gathered}
$$

At this point, we can turn to the choice of quantity $v s$. price competition made by the managers. In particular, the following table represents the strategic form of the game between managers on the choice of the competition regime where, for each case, $u=\pi+b q$ (the superscript 
referring to the unionisation regime has been omitted because the table applies qualitatively to both regimes).

\begin{tabular}{|c|c|c|}
\hline manager $i \backslash$ manager $j$ & Cournot & Bertrand \\
\hline Cournot & $u_{C}, u_{C}$ & $u_{C / B}, u_{B / C}$ \\
\hline Bertrand & $u_{B / C}, u_{C / B}$ & $u_{B}, u_{B}$ \\
\hline
\end{tabular}

Table 1: Endogenous competition choice by managers: strategic form

Proposition 2. When products are imperfect substitutes, the Cournot mode of competition is always the unique sub-game perfect equilibrium of the game between managers on the choice of the competition regime. Hence, irrespective of the unionisation structure, managers choose to compete on quantities even if competing in prices would generally lead to higher profits for the firms', owners.

Proof. See the final appendix.

It is worth noting that Proposition 2, according to which in the sub-game perfect equilibrium managers decide to compete in quantities when products are substitutes, is in line with the result of Singh and Vives (1984). There is, however, an important difference that should be remarked between the results obtained in the framework analysed herein (with managerial delegation and unionised labour markets) and Singh and Vives' (1984) standard duopoly with product differentiation. In the standard framework, the unique (endogenous) equilibrium coincides with the most profitable situation for firms' owners. Instead, in the presence of strategic delegation and a unionised labour market (irrespective of the structure of unionisation), the managers' choice of the type of contract offered to customers (or, in other words, the competition regime) is (generally) 
inefficient from the owners' viewpoint: while managers always opt for a quantity contract, profits are usually higher with price contracts. ${ }^{18}$

\section{Conclusions}

This paper dealt with the issue of the Cournot-Bertrand profit differential by bringing together two different strands of the industrial organisation literature: managerial delegation and unionised oligopolies. The issue was analysed under two alternative unionisation regimes, namely decentralised unionisation, involving firm-specific unions, and centralized unionisation, in which an industry-wide union sets a uniform wage for the entire sector. It was shown that, in contrast with the traditional result - that profits are higher when firms compete in quantities - obtained in a standard framework with profit-maximising firms and without unions, a "reversal result" generally applies (i.e. irrespective of the unionisation regime and for a very wide range of product differentiation) when we introduce managerial delegation and a unionised labour market into the analysis.

The "reversal result", however, is more likely to occur when unionisation is decentralised than centralised. Moreover, especially when products are not too much differentiated, the profit differential in favour of price competition is also larger in the presence of firm-specific unions. Some relevant policy and testable implications arise from those findings. For instance, since Bertrand competition is always associated also to a higher level of social welfare, policy makers should act to reduce the degree of centralisation in the union structure, at least when products are sufficiently substitutes. Moreover, markets characterized by competition in prices should be observed more frequently when the degree of wage setting centralisation is sufficiently low.

A key factor determining the results summarised above refers to a "wage effect" that applies in a managerial delegation framework in the presence of labour unions. In particular, the firms'

\footnotetext{
${ }^{18}$ In the presence of network externalities and managerial delegation (but without unions and with owners retaining the choice to compete in quantities or in prices), Chirco and Scrimitore (2013), Bhattacharjee and Pal (2013) and Pal (2015) obtain a more variegated set of equilibrium outcomes relative to the endogenous competition choice.
} 
owners have an incentive to manipulate the bonus weight for their managers not only to affect competition in the product market (the standard "competition effect" highlighted by the literature on managerial delegation), but also to dampen the unions' wage claim. It has been shown how such a wage effect generally drives owners to set a negative bonus weight in managerial contracts, i.e. to penalise managers for sales. Moreover, since by "penalising sales" the owners can obtain a larger wage reduction by unions, and sales penalisation is stronger when firms compete in prices, firms' profits prove to be higher under Bertrand than under Cournot competition for a much wider set of situations (i.e. parameter values) with respect to those identified by the literature.

Given the pivotal role that penalisation on sales plays for our results, it could be interesting to discuss briefly a situation where owners cannot penalise managers, that is, when a non-negativity constraint on the bonus weight applies. ${ }^{19}$ In this regard, while we have to leave the final answers to further research, some preliminary intuitions could arise by noting that, in all the regimes we considered, each firm's profit is an "inverted-U" function of the bonus weight of its manager. ${ }^{20}$ This implies that when the optimal choice by owners would provide for a negative bonus (we showed that this always applies when firms compete $\grave{a}$ la Bertrand and, under Cournot competition, unless unionisation is centralised and the degree of product substitutability is high), but this cannot be implemented because a "non-negative bonus" constraint applies, the "constrained-optimum" for owners is given by a zero bonus weight. However, such a situation corresponds to a standard unionised oligopoly model without managerial delegation (i.e. with profit-maximising firms), for which the results already established by the literature apply. Namely, under decentralised unionisation, we know from Correa-López and Naylor (2004) that the standard result (i.e. profits are higher with Cournot) always holds true when unions are total wage bill maximising. Although the situation under centralised unionisation is less obvious, preliminary analysis and speculation seem to

\footnotetext{
${ }^{19}$ Note, however, the possibility of penalising managers (not only for sales but even for profits) is contemplated by the literature on managerial delegation (e.g. Fershtman and Judd, 1987; Sklivas, 1987).

${ }^{20}$ This can be checked, for each case, from $\pi\left(b_{i}, b_{j}\right)$ taking $b_{j}\left(b_{i}\right)$ into account. For instance, in the case of decentralised unionisation and Cournot competition in the product market, by plotting (11) (or by deriving (11) with respect to $b_{i}$ ) taking the corresponding of (12) for $j$ into account.
} 
suggest that even in such a unionisation regime profits are always higher when firms compete in quantities if owners are constrained to set a non-negative bonus weight in managerial contracts. ${ }^{21}$

Besides comparing equilibrium profits taking competition regimes as given, we also investigated the endogenous choice of the competition regime by managers, assuming that also this choice is delegated to them by the firms' owners. Managers always choose to offer a quantity contract to customers (i.e. to compete à la Cournot), implying that their choice is (generally) inefficient for owners, since profits are usually higher with price contracts. Hence, this also suggests that owners could be better off by retaining for themselves the choice of the contract type to be offered to consumers, perhaps coordinating their decisions on a price contract. Obviously, this issue deserves to be tackled in greater detail by specifically investigating the game between owners (instead of between managers) on the choice of the (price or quantity) contract to offer in the downstream market, which is an interesting topic left to future research. Further possible extensions of this work could consist in analysing other types of managerial delegation contracts (e.g. "relative profit delegation" and "market share delegation"), multi-tasking delegation or introducing bargaining into the analysis.

\footnotetext{
${ }^{21}$ In particular, for the $\gamma$ values (i.e. $\gamma<0.7808$, see fn 13), for which the ("constrained-optimal") bonus choice would be zero in both competition regimes, the equilibrium profit under Cournot is $(4-2 \gamma)^{2} / 16(4-$ $\left.\gamma^{2}\right)^{2}$, while under Bertrand it is $\left(2 \gamma+2 \gamma^{2}-4\right)\left(4-2 \gamma-2 \gamma^{2}\right) / 16\left(4-\gamma^{2}\right)\left(1-\gamma^{2}\right)$ (they can be obtained from (23) and (28), respectively, with $b_{i}=b_{j}=0$ ) and it is easy to check that profit is always higher in the former regime. Instead, when $\gamma>0.7808$, we know from our analysis that profit is higher under Cournot even when owners (under Bertrand) are not constrained to set a non-negative bonus. Hence, we can expect that the standard profit-ranking holds a fortiori by introducing a non-negativity constraint on the bonus choice.
} 


\section{Appendix}

\section{A1 Proof of Proposition 1}

Relative to the decentralised unionisation regime, by defining the Cournot-Bertrand profit differential with $\Delta \pi^{D} \equiv \pi_{C}^{D}-\pi_{B}^{D}$, and taking profits in (14) and (20) into account, we get:

$$
\left.\begin{array}{l}
\Delta \pi^{D}= \\
\gamma^{2}\left(\begin{array}{l}
8 \gamma^{19}-8 \gamma^{18}-360 \gamma^{17}+388 \gamma^{16}+6521 \gamma^{15}-7191 \gamma^{14}-63930 \gamma^{13}+ \\
70330 \gamma^{12}+378136 \gamma^{11}-409976 \gamma^{10}-1405968 \gamma^{9}+1495488 \gamma^{8}+ \\
3289472 \gamma^{7}-3432192 \gamma^{6}-4664320 \gamma^{5}+4784128 \gamma^{4}+ \\
3629056 \gamma^{3}-3670016 \gamma^{2}-1179648 \gamma+1179648
\end{array}\right) \\
2(1+\gamma)\left(\gamma^{4}-\gamma^{3}-16 \gamma^{2}+8 \gamma-48\right)^{2}\left(4 \gamma^{7}-6 \gamma^{6}-37 \gamma^{5}+50 \gamma^{4}+102 \gamma^{3}-128 \gamma^{2}-80 \gamma+96\right)^{2} \\
<
\end{array}\right) \Leftrightarrow \gamma \frac{>}{<} 0.964 \equiv \bar{\gamma}^{D}
$$

Instead, relative to the centralised unionisation case, by defining with $\Delta \pi^{C} \equiv \pi_{C}^{C}-\pi_{B}^{C}$ the Cournot-Bertrand profit differential, and taking profits in (26) and (31) into account, we get:

$$
\begin{aligned}
& \Delta \pi^{C}= \\
& -\frac{\gamma^{2}\left(16 \gamma^{8}+33 \gamma^{7}-465 \gamma^{6}-297 \gamma^{5}+3113 \gamma^{4}+1560 \gamma^{3}-6872 \gamma^{2}-2576 \gamma+4368\right)}{4(1+\gamma)\left(2 \gamma^{3}-5 \gamma^{2}-7 \gamma+14\right)^{2}\left(\gamma^{2}-7 \gamma-14\right)^{2}} \geq 0 \Leftrightarrow \gamma \frac{\geq}{<} 0.761 \equiv \bar{\gamma}^{C}
\end{aligned}
$$

\section{A2 Proof of Proposition 2}

Consider the case in which unionisation is decentralised and let $\Delta_{1}^{D} \equiv u_{C / B}^{D}-u_{B}^{D}$ and $\Delta_{2}^{D} \equiv u_{B / C}^{D}-u_{C}^{D}$, with $u_{x}^{D}=\pi_{x}^{D}+b_{x}^{D} q_{x}^{D}$. Instead, for the case with centralised unionisation, let $\Delta_{1}^{C} \equiv u_{C / B}^{C}-u_{B}^{C}$ and $\Delta_{1}^{C} \equiv u_{B / C}^{C}-u_{C}^{C}$, where $u_{x}^{C}=\pi_{x}^{C}+b_{x}^{C} q_{x}^{C}$. Then Proposition 2 follows by noting that, as graphically shown by Figures A1 and A2 below, $\Delta_{1}^{D}>0, \Delta_{2}^{D}<0$ for any $\gamma \in(0,1)$, and $\Delta_{1}^{C}>0, \Delta_{2}^{C}<0$ for any $\gamma$ $\in(0,1)$. 

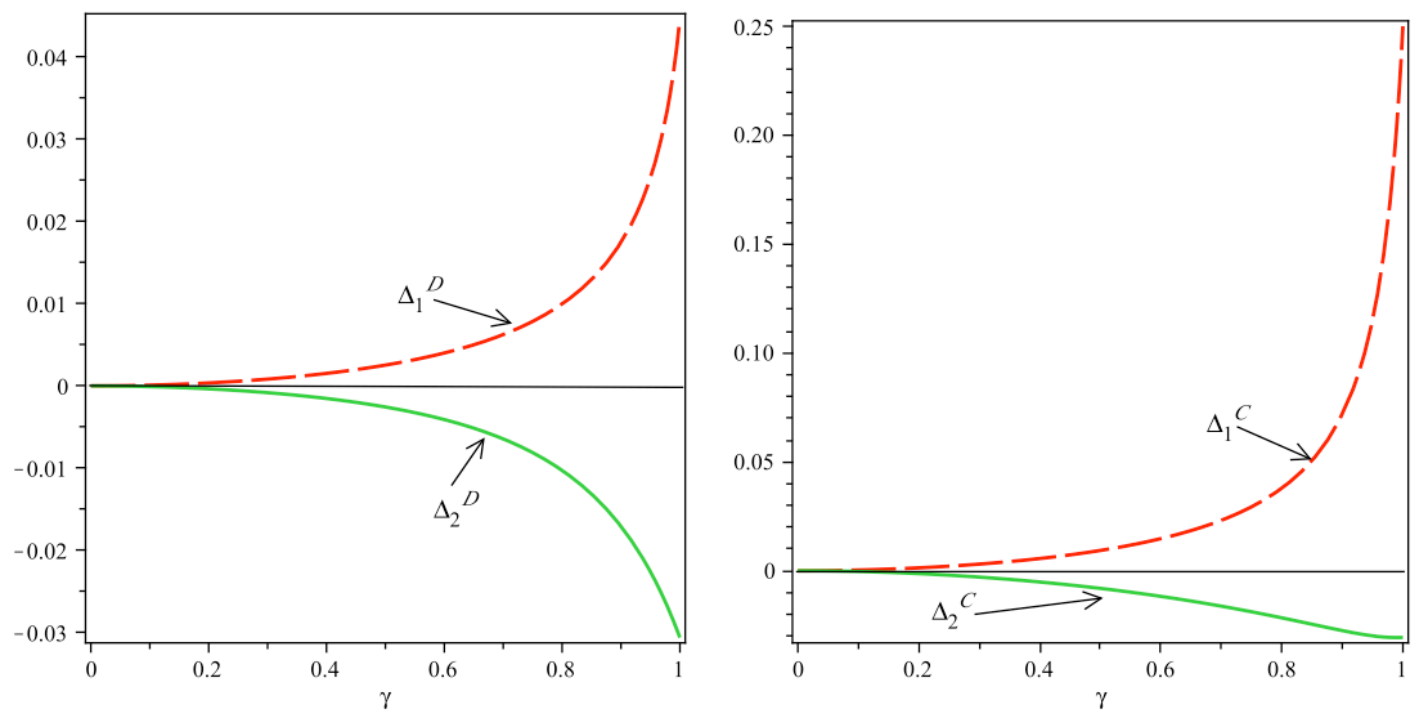

Figures A1-A2. Endogenous competition: managers' utility (key) differentials under alternative unionisation regimes: decentralised [left] and centralised [right]

\section{References}

Alipranti, M., Milliou, C. and Petrakis, E. (2014) Price vs. quantity competition in a vertically related market, Economics Letters 124, 122-126.

Amir, R. and Jin, J.Y. (2001). Cournot and Bertrand equilibria compared: substitutability, complementarity and concavity. International Journal of Industrial Organization 19, 303-317.

Bhattacharjee, T. and Pal, R. (2013). Price vs. quantity in duopoly with strategic delegation: role of network externalities. Indira Gandhi Institute of Development Research, Mumbai Working Papers 2013-010.

Berle, A.A. and Means, G.C. (1932). The Modern Corporation and Private Property. New York: Harcourt, Brace and World.

Bughin, J. (1995). Unions and strategic managerial incentives. Economics Letters 47, 95-100.

Calmfors, L. and Driffill, J. (1988). Centralisation and wage bargaining. Economic Policy 6, 13-61. 
Chang, R. and Peng, C. (2012). Comparing Bertrand and Cournot competition in a differentiated duopoly with technology licensing", Fu Jen Catholic University, Taiwan, mimeo.

Chatterjee, I. and Saha, B. (2011). Bilateral delegation, wage bargaining and managerial incentives: implications for efficiency and distribution. University of East Anglia AEP Discussion Papers in Economics 2011/28, University of East Anglia, Norwich, UK.

Cheng, L. (1985). Comparing Bertrand and Cournot equilibria: a geometric approach. RAND Journal of Economics 16, 146-152.

Chirco, A. and Scrimitore, M. (2013). Choosing price or quantity? The role of delegation and network externalities. Economics Letters 121, 482-486.

Choi, K. (2012). Price and quantity competition in a unionized mixed duopoly: the cases of substitutes and complements. Australian Economic Papers 51, 1-22.

Correa-López, M. (2007). Price and quantity competition in a differentiated duopoly with upstream suppliers. Journal of Economics \& Management Strategy 169, 469-505.

Correa-López, M. and Naylor, R.A. (2004). The Cournot-Bertrand profit differential: a reversal result in a differentiated duopoly with wage bargaining. European Economic Review 48, 681-696.

Dastidar, K.G. (1997). Comparing Cournot and Bertrand in a homogeneous product market. Journal of Economic Theory 75, 205-212.

Delbono, F. and Denicolò, V. (1990). R\&D investment in a symmetric and homogeneous oligopoly: Bertrand vs Cournot. International Journal of Industrial Organization 8, 297-313.

Dixit, A.K. (1979). A model of duopoly suggesting a theory of entry barriers. Bell Journal of Economics 10, 20-32.

Dowrick, S.J. (1989). Union-oligopoly bargaining. Economic Journal 99, 1123-1142.

Fanti, L. and Meccheri, N. (2011). The Cournot-Bertrand profit differential in a differentiated duopoly with unions and labour decreasing returns. Economics Bulletin 31, 233-244.

Fanti, L. and Meccheri, N. (2013a). Managerial delegation under alternative unionization structures. Labour 27, 38-57.

Fanti, L. and Meccheri, N. (2013b). Labour decreasing returns, industry-wide union and CournotBertrand profit ranking. A note. Economics Bulletin 32, 894-904.

Fershtman, C. (1985). Managerial incentives as a strategic variable in duopolistic environment. International Journal of Industrial Organization 3, 245-253. 
Fershtman, C. and Judd, K. (1987). Equilibrium incentives in oligopoly. American Economic Review 77, 927-940.

Flanagan, R.J. (1999). Macroeconomic performance and collective bargaining: an international perspective. Journal of Economic Literature 37, 1150-1175.

Freeman, R. (1988). Labour markets. Economic Policy 6, 63-80.

Ghosh, A. and Mitra, M. (2010). Comparing Bertrand and Cournot in mixed markets. Economics Letters 109, 72-74.

Ghosh, A. and Mitra, M. (2014). Reversal of Bertrand-Cournot rankings in the presence of welfare concerns. Journal of Institutional and Theoretical Economics 170, 496-519.

Häckner, J. (2000). A note on price and quantity competition in differentiated oligopolies. Journal of Economic Theory 93, 233-239.

Haucup, J. and Wey, C. (2004). Unionisation structures and innovation incentives. Economic Journal 114, 149-165.

Horn, H. and Wolinsky, A. (1988). Bilateral monopolies and incentives for merger. RAND Journal of Economics 19, 408-419

Jansen T., van Lier A. and van Witteloostuijn A. (2009) 'On the Impact of Managerial Bonus Systems on Firm Profit and Market Competition: The Cases of Pure Profit, Sales, Market Share and Relative Profits Compared', Managerial and Decision Economics 30: 141-153.

Klemperer, P. and Meyer, M. (1986). Price competition vs. quantity competition: the role of uncertainty. RAND Journal of Economics 17, 546-554.

Layard, R. and Nickell, S. (1999). Labor market institutions and economic performance. In Ashenfelter, O.C. and Card, D. (eds.), Handbook of Labor Economics, vol. 3, Amsterdam: North Holland.

Li, C. and $\mathrm{Ji}, \mathrm{X}$. (2010). Innovation, licensing, and price vs. quantity competition. Economic Modelling 27, 746-754.

Liao, P.-C. (2010). Strategic delegation under unionised duopoly: who will bargain with unions? Australian Economic Papers 49, 276-288.

Liao, P.-C. (2014). Strategic delegation of multiple tasks. Australian Economic Papers 53, 77-96.

Lommerud K.E., Straume, O.R. and Sørgard, L. (2005). Downstream merger with upstream market power. European Economic Review 49, 717-743. 
Manasakis, C. and Vlassis, M. (2014). Downstream mode of competition with upstream market power. Research in Economics 68, 84-93.

Matsumura, T. and Ogawa, A. (2012). Price versus quantity in a mixed duopoly. Economics Letters $116,174-177$.

Mauleon, A., Vannetelbosch, V.J. (2006). Strategic union delegation and incentives for merger. Applied Economics Letters 13, 1-5.

Meccheri, N. and Fanti, L. (2014). Managerial delegation contracts under centralized unionization. Managerial and Decision Economics 35, 51-66.

Miller, N. and Pazgal, A. (2001). The equivalence of price and quantity competition with delegation. RAND Journal of Economics 32, 284-301.

Motta, M. (1993). Endogenous quality choice: price vs. quantity competition. Journal of Industrial Economics 41, 113-131.

Mukherjee, A. (2011). Competition, innovation and welfare. The Manchester School 79, 1045-1057.

Mukherjee, A., Broll, S. and Mukherjee, S. (2012). Bertrand versus Cournot competition in a vertical structure: a note. The Manchester School 80, 545-559.

Naylor, R.A. (1999). Union wage strategies and international trade. Economic Journal 109, 102-125.

Nguyen, X., Sgro, P. and Nabin, M. (2014). Licensing under vertical product differentiation: price vs. quantity competition. Economic Modelling 36, 600-606.

Okuguchi, K. (1987). Equilibrium prices in the Bertrand and Cournot oligopolies. Journal of Economic Theory 42, 128-139.

Pal, R. (2010). Technology adoption in a differentiated duopoly: Cournot versus Bertrand. Research in Economics 64, 128-136.

Pal, R. (2014). Price and quantity competition in network goods duopoly: a reversal result. Economics Bulletin 34, 1019-1027.

Pal, R. (2015). Cournot vs. Bertrand under relative performance delegation: implications of positive and negative network externalities. Mathematical Social Sciences 75, 94-101.

Qiu, L.D. (1997). On the dynamic efficiency of Bertrand and Cournot equilibria. Journal of Economic Theory 75, 213-229.

Scrimitore, M. (2013). Price or quantity? The strategic choice of subsidized firms in a mixed duopoly. Economics Letters 118, 337-341. 
Scrimitore, M. (2014a). Quantity competition vs. price competition under optimal subsidy in a mixed oligopoly. Economic Modelling 42, 166-176.

Scrimitore, M. (2014b). Profitability under commitment in Cournot and Bertrand mixed markets. Journal of Institutional and Theoretical Economics 170, 684-703.

Singh, N. and Vives, X. (1984). Price and quantity competition in a differentiated duopoly. RAND Journal of Economics 15, 546-554.

Sklivas, S. (1987). The strategic choice of managerial incentives. RAND Journal of Economics 18, 452-458.

Symeonidis, G. (2003). Comparing Cournot and Bertrand equilibria in a differentiated duopoly with product R\&D. International Journal of Industrial Organization 21, 39-55.

Szymanski, S. (1994). Strategic delegation with endogenous costs. A duopoly with wage bargaining. International Journal of Industrial Organization 12, 105-116.

Tanaka, Y. (2001). Profitability of price and quantity strategies in an oligopoly. Journal of Mathematical Economics 35, 409-418.

van Witteloostuijn A., Jansen T. and van Lier A. (2007). Bargaining over managerial contracts in delegation games: managerial power, contract disclosure and cartel behavior', Managerial and Decision Economics 28, 897-904.

Vickers, J. (1985). Delegation and the theory of the firm. Economic Journal 95, 138-147.

Vives, X. (1985). On the efficiency of Bertrand and Cournot equilibria with product differentiation. Journal of Economic Theory 36, 166-175.

Wang, X.H. (2008). Price and quantity competition revisited. Economics Bulletin 4, 1-7.

Zanchettin, P. (2006). Differentiated duopoly with asymmetric costs. Journal of Economics \& Management Strategy 15, 999-1015. 